\title{
Ginkgolide B Inhibits Human Bladder Cancer Cell Migration and Invasion Through MicroRNA-223-3p
}

\author{
Yi Zhi Jinhong Pan Wenhao Shen Peng He Ji Zheng Xiaozhou Zhou \\ Gensheng Lu Zhiwen Chen Zhansong Zhou \\ Urology Institute of People Liberation Army, Southwest Hospital, the Third Military Medical University, \\ Chongqing, China
}

\section{Key Words}

Ginkgolide B (GB) • Bladder cancer • ZEB1 • miR-223-3p

\begin{abstract}
Background/Aims: Ginkgolide B (GB) is currently used as an anticancer drug for treatment of some malignant cancers. However, whether it may have therapeutic effects on bladder cancer remains unknown. Here, we studied the effects of $G B$ on bladder cancer cells. Methods: Bladder cells were treated with different doses of GB, and the effects on ZEB1 and microRNA-223-3p (miR-223-3p) were analyzed by RT-qPCR and/or Western blot. Prediction of a regulatory relationship between miR-93 and 3'-UTR of Beclin-1 mRNA was performed by a bioinformatics algorithm and confirmed by a dual luciferase reporter assay. Results: We found that GB dose-dependently decreased ZEB1 protein, but not MRNA, in bladder cancer cells, resulting in suppression of cell invasion. Moreover, in bladder cancer cells, GB dosedependently decreased the levels of miR-223-3p, which suppressed the protein translation of ZEB1 through binding to 3'-UTR of ZEB1 mRNA. Overexpression of miR-223-3p decreased ZEB1 protein, while depletion of miR-223-3p increased ZEB1 protein in bladder cancer cells. Conclusion: GB inhibits bladder cancer cell invasiveness through suppressing ZEB1 protein translation via upregulating miR-223-3p.
\end{abstract}

\section{Introduction}

Bladder cancer starts in the transitional epithelium of the bladder [1]. When the bladder cancer grows into or through the other layers in the bladder wall, it becomes more advanced and difficult to treat. Over time, the cancer may grow outside the bladder and spread to nearby lymph nodes, or to other parts of the body as distal metastases, leading to poor prognosis [1]. This feature of bladder cancer specifically emphasizes the importance of understanding the molecular mechanisms underlying the regulation of bladder cancer invasiveness. 
Epithelial-Mesenchymal Transition (EMT) is a critical biological event that triggers the modification of the cancer cell properties to allow cancer cell to adapt to a phenotype favoring invasiveness and metastases [2-5]. During EMT, cancer cells obtain capability of secreting proteinases from neighbor stromal cells or inflammatory cells for breaking through collagenous protein barriers. The EMT triggers include ZEB1, ZEB2, Snail1, Snail2 and E-cadherin [2-5]. The transcription factor ZEB1 possesses zinc-finger clusters in both the N-terminal and C-terminal regions, and a homeodomain in the central region, and appears to be a key promoter of EMT initiation and a key factor for maintaining the adapted mesenchymal phenotype [6]. The zinc-fingers of ZEB1 are essential for DNA-binding, by specific binding to an E-box sequence CACCTG [6]. Interestingly, ZEB1 has been shown to bind to the promoter of E-cadherin to repress its expression [6]. Nevertheless, the molecular pathway that regulates ZEB1 activation has been shown to be different in different cancers. Specifically, the signal pathways to control ZEB1 expression in bladder cancer cells are not clear.

MicroRNA (miRNA) is a class of 18-23-nucleotide non-coding small RNAs that regulate gene expression at translational level, through their base-pairing to the 3 -untranslated region (3'-UTR) of target mRNAs [7, 8]. It has been acknowledged that miRNAs play a role in the regulation of EMT-associated genes in the pathogenesis of various cancer [9-21]. However, whether miR-223-3p may play a role in the tumorigenesis of bladder cancer is unknown.

Recently, bioactive natural products have been used as anticancer medicine. Ginkgolide B (GB) is a component of ginkgo leaf, which has been widely used for treating asthma, cough and enuresis $[22,23]$. Previous studies have shown that GB has beneficial effects on endothelial cell protection [24] as well as cancer therapy [25-27]. However, whether GB may have an anti-bladder cancer effect is not known.

Here, we studied the effects of GB on bladder cancer cells and the underlying mechanism.

\section{Materials and Methods}

\section{Protocol approval}

All experiments were carried out in strict accordance with the regulations in the guide for the experimental research issued by the Third Military Medical University. The protocol was approved by the Institutional Animal Care and Use Committee of the Third Military Medical University.

\section{Cell line, transfection and reagents}

A human bladder cancer cell line T24 was purchased from ATCC (American Type Culture Collection, Manassas, VA, USA), and have been widely used in bladder cancer cell research. T24 was generated from an 81-year-old female Caucasian [28] and was cultured in in RPMI1640 medium (Invitrogen, Carlsbad, CA, USA) supplemented with 15\% fetal bovine serum (FBS; Sigma-Aldrich, St Louis, MO, USA) in a humidified chamber with $5 \% \mathrm{CO}_{2}$ at $37^{\circ} \mathrm{C}$. MiRNAs mimics (miR-223-3p), miRNAs antisense oligonucleotides (as-miR223-3p), ZEB1, and short hairpin small interfering RNA for ZEB1 (shZEB1) were obtained from Origene (Beijing, China).

These constructs were generated and cloned into the TOPO plasmid (Invitrogen, Carlsbad, CA, USA). Plasmids carrying a null sequence (null) or a scramble sequence (scr) was used as a control. The plasmids were transfected into cells at a concentration of 50 nmol/l using Lipofectamine-2000 (Invitrogen), receiving a 95\% transfection efficiency. The cells were analyzed after 24 hours, according to the manufacturer's instruction. GB (Sigma-Aldrich) was prepared in a stock of $100 \mathrm{mmol} / \mathrm{l}$ in DMSO and applied to the cultured T24 cells at $0,0.5,1$ and $2 \mathrm{mmol} / \mathrm{l}$, respectively.

Quantitative PCR (RT-qPCR)

Total RNA was extracted from the cultured cells using miRNeasy mini kit (Qiagen, Hilden, Germany). For cDNA synthesis, complementary DNA (cDNA) was randomly primed from $2 \mu \mathrm{g}$ of total RNA using the Omniscript reverse transcription kit (Qiagen). RT-qPCR was subsequently performed in triplicate with a 1:4 


\section{Cellular Physiology Cell Physiol Biochem 2016;39:1787-1794 \begin{tabular}{ll|l} 
DOI: 10.1159/000447878 & $\begin{array}{l}\text { O 2016 The Author(s). Published by S. Karger AG, Basel } \\
\text { www.karger.com/cpb }\end{array}$
\end{tabular} \\ Zhi et al.: Anti-Bladder Cancer Effect of GB}

dilution of cDNA using the Quantitect SyBr green PCR system (Qiagen). All primers were purchased from Qiagen. Data were collected and analyzed using ${ }^{2-\Delta \Delta} \mathrm{C}$ method. Values of genes were first normalized against $\alpha$-tubulin, and then compared to the experimental controls.

\section{Western blot}

The protein was extracted from the cultured cells, and homogenized in RIPA lysis buffer (1\% NP40, $0.1 \%$ SDS, $100 \mu \mathrm{g} / \mathrm{ml}$ phenylmethylsulfonyl fluoride, $0.5 \%$ sodium deoxycholate, in PBS) on ice. The supernatants were collected after centrifugation at $12000 \times \mathrm{g}$ at $4^{\circ} \mathrm{C}$ for $20 \mathrm{~min}$. Protein concentration was determined using a BCA protein assay kit (Bio-rad, China), and whole lysates were mixed with $4 \times$ SDS loading buffer (125mmol/l Tris-HCl, 4\% SDS, 20\% glycerol, $100 \mathrm{mmol} / \mathrm{l}$ DTT, and $0.2 \%$ bromophenol blue) at a ratio of $1: 3$. Protein samples were heated at $100^{\circ} \mathrm{C}$ for $5 \mathrm{~min}$ and were separated on SDS-polyacrylamide gels. The separated proteins were then transferred to a PVDF membrane. The membrane blots were first probed with a primary antibody. After incubation with horseradish peroxidase-conjugated second antibody, autoradiograms were prepared using the enhanced chemiluminescent system to visualize the protein antigen. The signals were recorded using X-ray film. Primary antibodies for Western Blot are anti-ZEB1 and $\alpha$-tubulin (all from Cell Signaling, San Jose, CA, USA). $\alpha$-tubulin was used as protein loading controls. Secondary antibody is HRP-conjugated anti-rabbit (Jackson ImmunoResearch Labs, West Grove, PA, USA). Images shown in the figures were representative from 5 individuals. Densitometry of Western blots was quantified with NIH Image J software (Bethesda, MA, USA). The protein levels were first normalized to $\alpha$-tubulin, and then normalized to experimental controls.

MicroRNA target prediction and luciferase-reporter activity assay

MiRNAs targets were predicted using the algorithms TargetSan (https://www.targetscan.org). Luciferase-reporters were successfully constructed using molecular cloning technology. Target sequence was inserted into pGL3-Basic vector (Promega) to obtain pGL3-ZEB1-3'-UTR containing the miR-223-3p binding sequence (ZEB1-3'-UTR sequence). MiR-223-3p-modified T24 cells were seeded in 24-well plates for 24 hours, after which they were transfected with $1 \mu \mathrm{g}$ of Luciferase-reporter plasmids per well using PEI Transfection Reagent. Then luciferase activities were measured using the dual-luciferase reporter gene assay kit (Promega), according to the manufacturer's instructions.

\section{Transwell cell invasion assay}

The transwell cell invasion assay was performed using a Fluorometric Cell Migration Assay kit with polycarbonate membrane inserts $(5 \mu \mathrm{m}$ pore size; Cell Biolabs, San Diego, CA, USA). Cells were serumstarved overnight in DMEM prior to initiation of the experiment. The lower chambers were filled with $1 \mathrm{ml}$ of conditioned media. Cells $\left(4 \times 10^{4}\right)$ were re-suspended in $200 \mu \mathrm{l}$ of DMEM and added to the upper chamber. Cells were then incubated at $37^{\circ} \mathrm{C}$ for 24 hours to allow cell migration through the membrane. Migratory cells were detached from the underside of the membrane and subsequently lysed and detected by CyQuant GR dye (Invitrogen). Fluorescence measurement was performed in a FluoStar Optima fluorescence plate reader with a $485 / 520 \mathrm{~nm}$ filter set.

\section{Statistics}

All statistical analyses were carried out using the GraphPad Prism 6.0 statistical software package (GraphPad Software, Inc. La Jolla, CA, USA). All values are depicted as mean \pm standard deviation (SD) and are considered significant if $\mathrm{p}<0.05$. All data were statistically analyzed using one-way ANOVA with a Bonferroni correction, followed by Fisher' Exact Test for comparison of two groups.

\section{Results}

GB dose-dependently reduces ZEB1 protein level, but not mRNA level, in bladder cancer cells, resulting in suppression of cell invasion

A human bladder cancer cell line, T24, was kept in culture and then treated with different doses of GB for 24 hours, after which the cellular levels of ZEB1 were measured. We found that GB dose-dependently decreases ZEB1 protein levels (Fig. 1A). However, the 
Fig. 1. GB dose-dependently decreases ZEB1 protein, but not mRNA, in bladder cancer cells, resulting in suppression of cell invasion. A human bladder cancer cell line, T24, was kept in culture and then treated with different doses of GB for 24 hours, after which the cellular levels of ZEB1 were measured. (A) Western blot for ZEB1 protein. (B) RT-qPCR for ZEB1 mRNA. (C-D) A transwell cell invasion assay for GB-treated T24 cells, shown by quantification (C) and by representative images (D). ${ }^{*} \mathrm{p}<0.05$. NS: non-significant. $\mathrm{N}=5$.

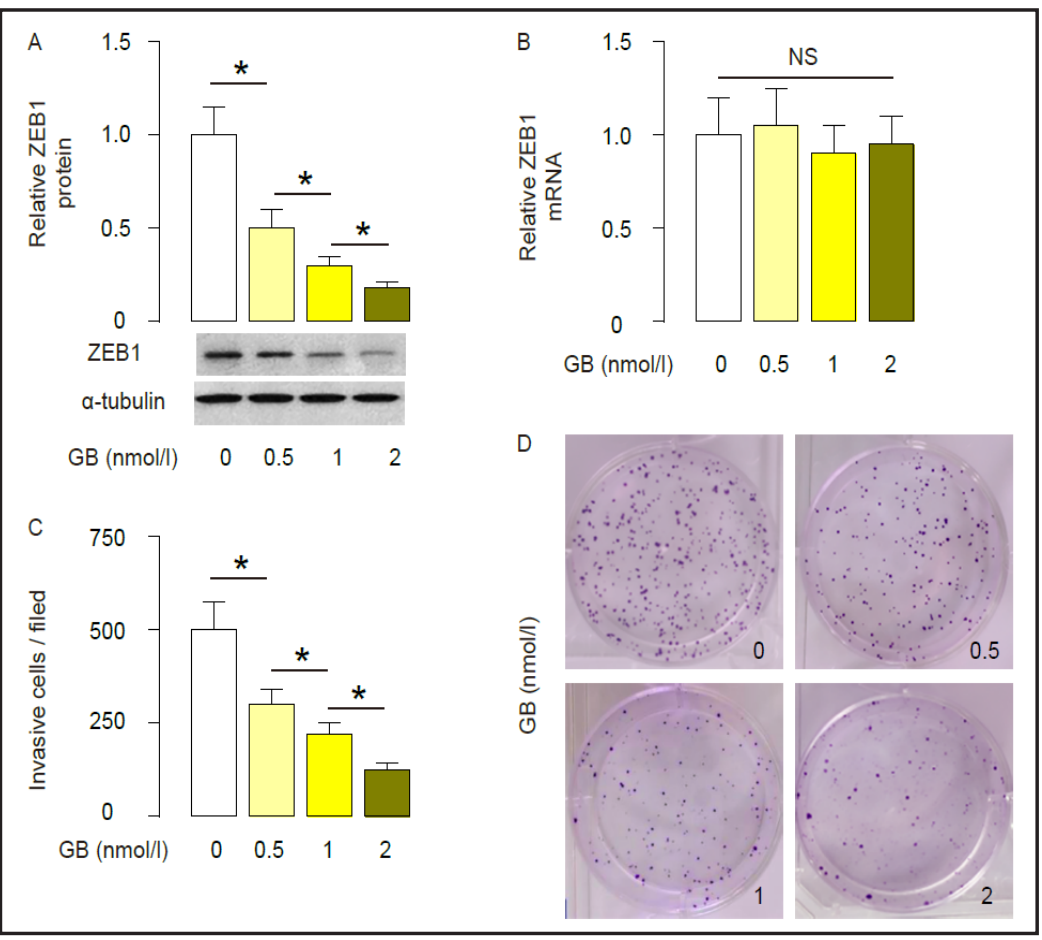

Fig. 2. Overexpression of ZEB1 abolishes the GB-induced suppression of bladder cancer cell invasiveness. We either overexpressed or depleted ZEB1 in T24 cells. (A-B) RT-qPCR for ZEB1 mRNA (A) and Western blot (B) for ZEB1 levels in ZEB1-modified T24 cells. (C) A transwell cell invasion assay for ZEB1-modified T24 cells. +: present; -, not present. ${ }^{*} \mathrm{p}<0.05$. NS: non-significant. $\mathrm{N}=5$.

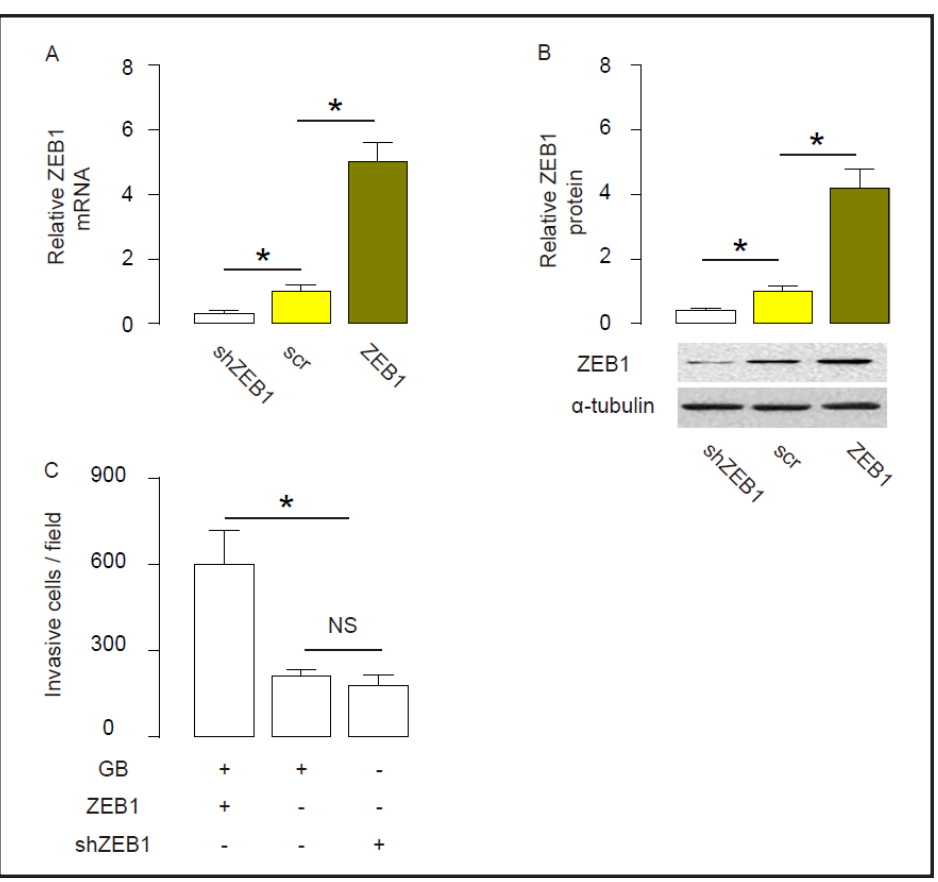

mRNA levels of ZEB1 were not altered by GB treatment (Fig. 1B), suggesting that GB may regulate ZEB1 at translational level. Next, we examined the effects of GB on cell invasion in a transwell cell invasion assay. We found that GB dose-dependently decreased the cell invasion (Fig. 1C-D). Together, these data suggest that GB may decrease ZEB1 protein level in bladder cancer cells to suppress cell invasion.

ZEB1 overexpression abolishes the GB-induced suppression of bladder cancer cell invasion

In order to confirm that changes in ZEB1 levels is responsible for the alteration in bladder cancer cell invasion, we either overexpressed or depleted ZEB1 in T24 cells. First, we confirmed the alteration of ZEB1 levels in T24 cells, by RT-qPCR (Fig. 2A), and by Western 
Fig. 3. The effects of $\mathrm{GB}$ on ZEB1 are mediated through miR-223-3p. (A) Bioinformatics analyses showing that miR-223-3p binds to 3'-UTR of ZEB1 mRNA. (B) GB dose-dependently increased the levels of miR-223-3p in T24 cells. (CD) We transfected T24 cells by plasmids carrying either miR223-3p, or as-miR-223-3p, or null as a control. (C) The modification of miR-223-3p levels in T24 cells was confirmed by RT-qPCR. (D) The miR-223-3pmodified T24 cells were transfected with $1 \mu \mathrm{g}$ of ZEB1-3'-UTR Luciferase-reporter plasmid, and the luciferase activities were quantified. ${ }^{*} \mathrm{p}<0.05 . \mathrm{N}=5$.

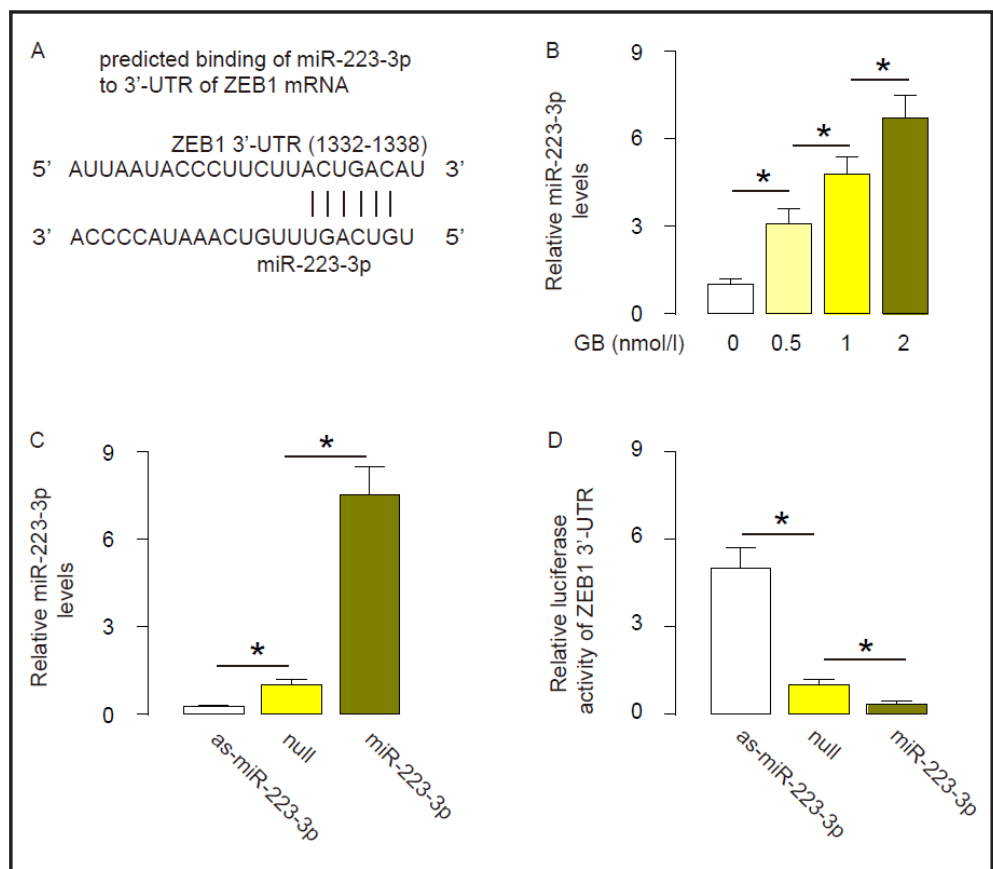

Fig. 4. MiR-223-3p-mediated suppression of ZEB1 decreases bladder cancer cell invasion. We either overexpressed or depleted miR-223-3p in T24 cells. (A-B) RT-qPCR for ZEB1 mRNA (A) and Western blot for ZEB1 protein (B) in miR223-3p-modified T24 cells. (C) A transwell cell invasion assay for miR-223-3p-modified T24 cells. ${ }^{*} p<0.05$. NS: non-significant. $\mathrm{N}=5$.

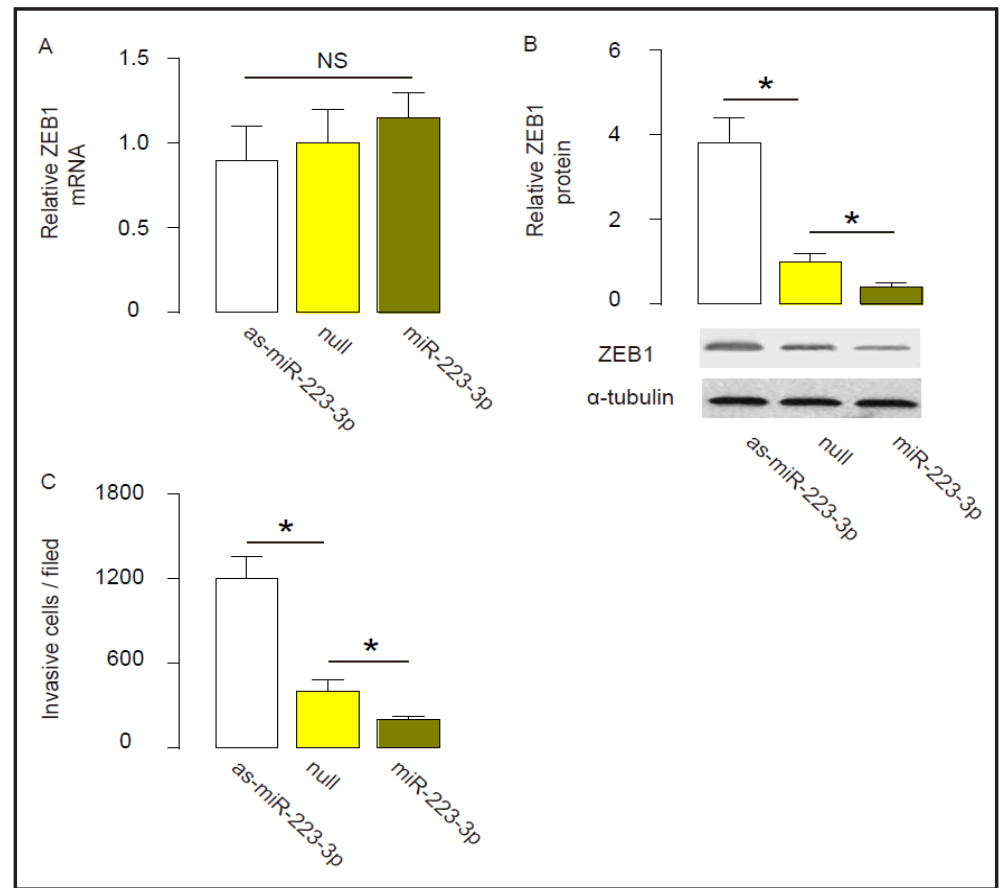

blot (Fig. 2B). We found that ZEB1 overexpression in bladder cancer cells abolished the GBinduced suppression of bladder cancer cell invasion, while depletion of ZEB1 in bladder cancer cells mimicked the effects of GB on cell invasion (Fig. 2C).

The suppressive effects of GB on ZEB1 are mediated through miR-223-3p

Since GB altered protein, but not mRNA levels of ZEB1, we hypothesize that GB may control ZEB1 at translation level. Thus, we screened all ZEB1-targeting miRNAs, which were altered by GB treatment. Specifically, we found that miR-223-3p bound to 3'-UTR of ZEB1 mRNA (Fig. 3A), and GB dose-dependently increased the levels of miR-223-3p in T24 cells (Fig. 3B). In order to understand the biological relevance of the binding between 
miR-223-3p and 3'-UTR of ZEB1 mRNA, we transfected T24 cells by plasmids carrying either miR-223-3p, or as-miR-223-3p, or null as a control. The modification of miR-223-3p levels in T24 cells was confirmed by RT-qPCR (Fig. 3C). Afterwards, these miR-223-3pmodified T24 cells were transfected with $1 \mu \mathrm{g}$ of ZEB1-3'-UTR Luciferase-reporter plasmid. We found that the luciferase activities in miR223-3p-depleted T24 cells were significantly higher than the control, while the luciferase activities in miR-223-3p-overexpressing

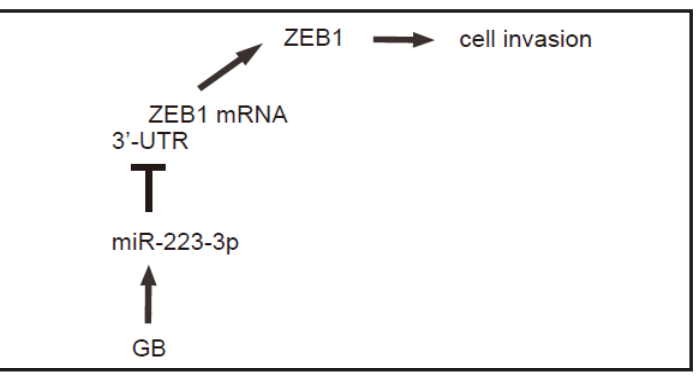

Fig. 5. Schematic of the model. GB may suppress bladder cancer cell invasiveness through miR-223-3p-regulated ZEB1 protein translation. T24 cells were significantly lower than the control (Fig. 3D). Together, these data suggest that miR-223-3p may targets 3'-UTR of ZEB1 mRNA to inhibit its translation in bladder cancer cells. Moreover, GB may induce miR-223-3p to suppress ZEB1 in bladder cancer cell, resulting in cell invasion arrest.

MiR-223-3p-mediated suppression of ZEB1 decreases bladder cancer cell invasion

We found that modulation of miR-223-3p in T24 cells did not alter mRNA levels of ZEB1 (Fig. 4A). However, overexpression of miR-223-3p decreased ZEB1 protein (Fig. 4B), resulting in deecreases in cell invasion (Fig. 4C). On the other hand, depletion of miR-223$3 p$ increased ZEB1 protein (Fig. 4B), resulting in increases in cell invasion (Fig. 4C). These data suggest that miR-223-3p-mediated suppression of ZEB1 inhibits bladder cancer cell invasion (Fig. 5).

\section{Discussion}

The efficacy of chemotherapy for bladder cancer is limited. Therefore, the development of new agents for bladder cancer treatment is in urgent need. Recent years, anti-cancer agents extracted from Chinese herb have continuously attracted attention.

GB is a component of ginkgo leaf, and previous studies have provided evidence for a chemo-preventive or a therapeutic effect of GB on ovarian cancer [29]. In our study, we investigated the effects of GB on the invasiveness in human T24 bladder cancer cells in vitro. The dose of GB used for enhancing the sensitivity of chemotherapy in ovarian cancer is relatively low. However, the dose used for reducing oxidative stress in umbilical vein endothelial cells is very high [30]. Here, we chose to use $500-2000 \mathrm{nmol} / \mathrm{l}$ as the experimental dose.

Here, we found that GB dose-dependently increased ZEB1 protein, but not mRNA, in human Bladder cancer T24 cells. These data suggest the presence of the post-transcriptional control of ZEB1, which is regulated by GB. Our next approaches showed that overexpression of ZEB1 in T24 cells abolished the suppression of cell invasion by GB. Moreover, we found that GB dose-dependently increased miR-223-3p, which bound to 3'-UTR of ZEB1 mRNA to inhibit its translation. MiR-223-3p was identified as the key miRNA that suppresses ZEB1 from all ZEB1-targeting miRNAs through examination of their expression before and after GB treatment. Overexpression of miR-223-3p decreased ZEB1, resulting in decreases in cell invasion. On the other hand, depletion of miR-223-3p increased ZEB1, resulting in increases in cell invasion. When a miRNA molecule perfectly matches to a target mRNA, it causes the mRNA degradation to result in decreases in the mRNA levels by RT-qPCR. Here, we seemed to obtain a partial interaction between the miR-223-3p and the 3'-UTR of the ZEB1 gene. In case that the miRNA does not form a perfect match with the target RNA, the translation process stops at that point and hence the protein production is reduced, as described here. Of note, we have examined several other bladder cancer cell lines and obtained essentially same results. Thus, our results do not appear to cell-line dependent. 


\section{Cellular Physiology Cell Physiol Biochem 2016;39:1787-1794

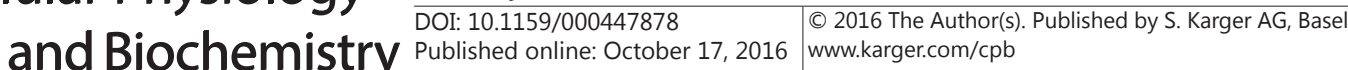 \\ Zhi et al.: Anti-Bladder Cancer Effect of GB}

In future, it may be interesting to also examine the effects of GB on cell viability, as well as the underlying mechanisms like cell proliferation, apoptosis, autophagy, as indicated by previous studies. Furthermore, future approaches may be also designed to elucidate the precise mechanisms underlying the regulation of miR-223-3p by GB. In addition, it is possible that miR-223-3p may have targets other than ZEB1 that are also involved in this model. Examination of these targets of miR-223-3p may improve the completeness of our understanding of the role of miR-223-3p in control of bladder cancer cell invasion.

In summary, our data demonstrate a previously unappreciated role of miR-223-3p in the regulation of ZEB1-mediated cell invasion, and propose that GB may have a therapeutic potential to reduce the invasion of bladder cancer cells.

\section{Acknowledgement}

This work is supported by National Natural Science Foundation of China (NO: 81302222) and Natural Science Foundation of Chongqing (cstc2013jcyjA10141).

\section{Disclosure Statement}

The authors have declared that no competing interests exist.

\section{References}

1 Martyn-Hemphill C, Mak D, Khan MS, Challacombe BJ, Bishop CV: Recent advances in diagnosis and treatment of transitional cell carcinoma of the bladder. Int J Surg 2013;11:749-752.

2 Hu Q, Tong S, Zhao X, Ding W, Gou Y, Xu K, Sun C, Xia G: Periostin mediates tgf-beta-induced epithelial mesenchymal transition in prostate cancer cells. Cell Physiol Biochem 2015;36:799-809.

3 Sa Y, Li C, Li H, Guo H: Timp-1 induces alpha-smooth muscle actin in fibroblasts to promote urethral scar formation. Cell Physiol Biochem 2015;35:2233-2243.

4 Lan A, Qi Y, Du J: Akt2 mediates tgf-beta1-induced epithelial to mesenchymal transition by deactivating gsk3beta/snail signaling pathway in renal tubular epithelial cells. Cell Physiol Biochem 2014;34:368-382.

5 Teng Y, Zhao L, Zhang Y, Chen W, Li X: Id-1, a protein repressed by mir-29b, facilitates the tgfbeta1-induced epithelial-mesenchymal transition in human ovarian cancer cells. Cell Physiol Biochem 2014;33:717-730.

6 Schmalhofer 0, Brabletz S, Brabletz T: E-cadherin, beta-catenin, and zeb1 in malignant progression of cancer. Cancer Metastasis Rev 2009;28:151-166.

7 Di Leva G, Croce CM: Mirna profiling of cancer. Curr Opin Genet Dev 2013;23:3-11.

8 Pereira DM, Rodrigues PM, Borralho PM, Rodrigues CM: Delivering the promise of mirna cancer therapeutics. Drug Discov Today 2013;18:282-289.

9 Kim YW, Kim EY, Jeon D, Liu JL, Kim HS, Choi JW, Ahn WS: Differential microrna expression signatures and cell type-specific association with taxol resistance in ovarian cancer cells. Drug Des Devel Ther 2014;8:293314.

10 Wang Y, Zang W, Du Y, Ma Y, Li M, Li P, Chen X, Wang T, Dong Z, Zhao G: Mir-655 up-regulation suppresses cell invasion by targeting pituitary tumor-transforming gene- 1 in esophageal squamous cell carcinoma. J Transl Med 2013;11:301.

11 Kitamura K, Seike M, Okano T, Matsuda K, Miyanaga A, Mizutani H, Noro R, Minegishi Y, Kubota K, Gemma A: Mir-134/487b/655 cluster regulates tgf-beta-induced epithelial-mesenchymal transition and drug resistance to gefitinib by targeting magi2 in lung adenocarcinoma cells. Mol Cancer Ther 2014;13:444-453.

12 Harazono Y, Muramatsu T, Endo H, Uzawa N, Kawano T, Harada K, Inazawa J, Kozaki K: Mir-655 is an emtsuppressive microrna targeting zeb1 and tgfbr2. PLoS One 2013;8:e62757.

13 Ying X, Wei K, Lin Z, Cui Y, Ding J, Chen Y, Xu B: Microrna-125b suppresses ovarian cancer progression via suppression of the epithelial-mesenchymal transition pathway by targeting the set protein. Cell Physiol Biochem 2016;39:501-510. 


\section{Cellular Physiology Cell Physiol Biochem 2016;39:1787-1794 \begin{tabular}{ll|l} 
DOI: 10.1159/000447878 & $\begin{array}{l}\text { O 2016 The Author(s). Published by S. Karger AG, Basel } \\
\text { www.karger.com/cpb }\end{array}$
\end{tabular} \\ Zhi et al.: Anti-Bladder Cancer Effect of GB}

14 Lin L, Tu HB, Wu L, Liu M, Jiang GN: Microrna-21 regulates non-small cell lung cancer cell invasion and chemo-sensitivity through smad7. Cell Physiol Biochem 2016;38:2152-2162.

15 Li P, Sun Y, Liu Q: Microrna-340 induces apoptosis and inhibits metastasis of ovarian cancer cells by inactivation of nf-x03ba;b1. Cell Physiol Biochem 2016;38:1915-1927.

16 Zhou L, Xu Z, Ren X, Chen K, Xin S: Microrna-124 (mir-124) inhibits cell proliferation, metastasis and invasion in colorectal cancer by downregulating rho-associated protein kinase 1(rock1). Cell Physiol Biochem 2016;38:1785-1795.

17 Ma T, Zhao Y, Wei K, Yao G, Pan C, Liu B, Xia Y, He Z, Qi X, Li Z, Wang J, Shao Y: Microrna-124 functions as a tumor suppressor by regulating cdh2 and epithelial-mesenchymal transition in non-small cell lung cancer. Cell Physiol Biochem 2016;38:1563-1574.

18 Wang G, Cai C, Chen L: Microrna-3666 regulates thyroid carcinoma cell proliferation via met. Cell Physiol Biochem 2016;38:1030-1039.

19 Sun JJ, Chen GY, Xie ZT: Microrna-361-5p inhibits cancer cell growth by targeting cxcr6 in hepatocellular carcinoma. Cell Physiol Biochem 2016;38:777-785.

20 Chen G, Fang T, Huang Z, Qi Y, Du S, Di T, Lei Z, Zhang X, Yan W: Microrna-133a inhibits osteosarcoma cells proliferation and invasion via targeting igf-1r. Cell Physiol Biochem 2016;38:598-608.

21 Gao Y, Feng B, Han S, Zhang K, Chen J, Li C, Wang R, Chen L: The roles of microrna-141 in human cancers: From diagnosis to treatment. Cell Physiol Biochem 2016;38:427-448.

22 Smith JV, Luo Y: Studies on molecular mechanisms of ginkgo biloba extract. Appl Microbiol Biotechnol 2004;64:465-472.

23 Zimmermann M, Colciaghi F, Cattabeni F, Di Luca M: Ginkgo biloba extract: From molecular mechanisms to the treatment of alzhelmer's disease. Cell Mol Biol (Noisy-le-grand) 2002;48:613-623.

24 Maclennan KM, Darlington CL, Smith PF: The cns effects of ginkgo biloba extracts and ginkgolide b. Prog Neurobiol 2002;67:235-257.

25 Kang JW, Kim JH, Song K, Kim SH, Yoon JH, Kim KS: Kaempferol and quercetin, components of ginkgo biloba extract (egb 761), induce caspase-3-dependent apoptosis in oral cavity cancer cells. Phytother Res 2010;24:S77-82.

26 Kwon SH, Nam JI, Kim SH, Kim JH, Yoon JH, Kim KS: Kaempferol and quercetin, essential ingredients in ginkgo biloba extract, inhibit interleukin-1beta-induced muc5ac gene expression in human airway epithelial cells. Phytother Res 2009;23:1708-1712.

27 Xu AH, Chen HS, Sun BC, Xiang XR, Chu YF, Zhai F, Jia LC: Therapeutic mechanism of ginkgo biloba exocarp polysaccharides on gastric cancer. World J Gastroenterol 2003;9:2424-2427.

28 Bubenik J, Baresova M, Viklicky V, Jakoubkova J, Sainerova H, Donner J: Established cell line of urinary bladder carcinoma (t24) containing tumour-specific antigen. Int J Cancer 1973;11:765-773.

29 Ye B, Aponte M, Dai Y, Li L, Ho MC, Vitonis A, Edwards D, Huang TN, Cramer DW: Ginkgo biloba and ovarian cancer prevention: Epidemiological and biological evidence. Cancer Lett 2007;251:43-52.

30 Ma L, Liu X, Zhao Y, Chen B, Li X, Qi R: Ginkgolide b reduces lox-1 expression by inhibiting akt phosphorylation and increasing sirt1 expression in oxidized ldl-stimulated human umbilical vein endothelial cells. PLoS One 2013;8:e74769. 